ditions which you know by your experience and your training to contribute most to the development of health. In the second place comes in the something which traverses these laws; and that something is the defect in the organism. It is not enough to say to a man with renal inadequacy exactly what you wonld say to a man who had no recognisable defect in his organism. You wonld say to him, "That and drink, and take exercise, be warmly clothed, have snfioient sleep, do your appointed work, and have no fear." It would not do to say that quite to a man with renal inadequacy. So that, although the first rule to be laid for the individual with regard to the physiological laws which subserve the health remains, it must be plus those modifications which the defect in the organism requires. You would not mind a man pursuing an active course of vigorous life eating a pound of meat a day; but if you allowed a man with renal inadequacy to eat a pound of meat a day, it would certainly kill him. So that the second rule about these cases is that, whilst laying down the simple physiological laws of simplicity and regularity of diet, you will modify these laws so far as the kidney is concerned, because you know that it is the business of the kidney to throw out chiefly azotised waste, and you will be careful to supply the organism with no more of such azotised matter than is needful for the maintenance of its integrity. We all supply to ourselves a good deal more than is necessary for the integrity of onr organs; and fortunately in health the margin of oscillation is 80 wide that we need not be over-scrupulous; but, in a case of this kind, the whole future for evil or for good will depend upon whether we fully recognise that law of modification which the defect of the organism requires.

What, then, would be the general rule for such cases as I have described? In the first place I should say to myself-"I must take care that I do not give to this patient more azotised food than is nccessary for the maintenance of the integrity of the organism; in the next place, I must take care that I get all the supplementary, complementary, excretory organs to do fully their appointed work, that they may, if possible, take some share of the defective work of the kidney upon their shoulders." Then I should take care also to give no agent in my dietary which would be calculatel to check, or seriously to check excretions; I should furthermore take care in dealing with my patient, that, as he is very vulnerable and very liable to inflammations brought on by chills, or by wet, or by what preople call over exertion, to cantion him about these points. And further, as these tissues are vulnerable from all sides, I should recommend him not to take violent excrcise. Taking these principles, and applying them in detail, my advice in the casc of a man who came before me, say forty-five years of age, would be something like this. I should ask him-“ Now, yon have a defect in your body, and you must take care not to make that defect groater, but do all you can to remedy it, and this is what you will do. When you get up in the morning sponge yourself with warm water and use a little soap ; do it quickly that you may not get a chill, have a good rubbing afterwards, so as to make the skin act as wcll as it can act." Then I should tell him to clothe warmly, not over-warmly 80 as to wenken the skin, but sufficiently warmly to protect him frow the vicissitucles of such a climate as this. Then I should say to him-"You will hare three meals a day, and these mcals must be something after this fashion, for as your chimney is choked, you must not put too many coals on the fire. You will take for your breakfast bread and butter-plenty of butter if you like it, and an egg, if not nervous a cup of tea, which has not stood too long, or if very nervous a cup of cocoa; then you will dine in the middle of the day." If he were a very were a stupid patient, and most patients are stupid, I should say"Take a little meat, not more than half a pound by any means, with plenty of potatoes or other regetables, and you may have some pudding." With regard to drink, I should give him as little alcohol as I found the intellectual strength or wisdom of the man would bear. If he were a very wise man I should say-"Yon will do best to take none;" but if he were not a very wisc man I should strengthen him in his foolishness by giving him a glass of claret and water. Then I should say-" You can have one more meal in the evening, about six or seven o'clock, and yon will take for it just what you do for your breakfast-bread and buttcr, and pcrhaps an egg - or a tiny bit of fish or the wing of a chicken, with a cup of tca, or if sleepless or nervous a cup of cocoa." And I should allow mornings and the same on going to bed at night. Now this seems to be a vexy reasonable diet, but'I will confess to jou that I have iost many a pátient by prescribing it. When people hare looked at that dietary, which sometimes I have written down, they lave been amased at it. I have in my mind's eye a great man who had sprung from the people and made himself wealthy by his own exertions, but who, not being a man of culture or intellectual tendencies generally, wanted to have his heart's desire in the reward of success. He looked at my ldietary, and said to me-" Good hearens, sir! is this the reward of success in life? What is to become of me?" Neverthelcss, I think it a sufficiently liberal dietary for any organism which is at all crippled, and I am not prepared to say that it is not a sufficiently liberal dietary for any man who leads a sedentary life, and wishes to make the best of his brains and his strength.

I have detained you very long, and I will not detain you many minutes more. I will just say, in looking over these cases, which I think form a considerable percentage of ailing people-I do not know how many, because my experience is not large enough to say -I believe it is in our power to do an immense deal of good for them if we are firm in asserting what we know to be correct, and if we can gain the confidence of the patient so that he will follow what we suggest. I am sure that in our dealing with these cases many valuable lives might be preserved if we had the courage to face the accusation, of being, as $I \mathrm{am}$, a starving rloctor.

\section{CLINICAL LECTURES ON DISEASES OF THE NERVOUS SYSTEM.}

BY A. HUGHES BENNETT, M.D.,

Plysician to the Hoopital for Epilepsy and Paralysis, Regent s Park, and Assistant-Physician to the Westminster Hospital.

On a Case of Peripheral Disease of the Facial and Mypoglossal Nerves on both sides, the Symptoms simulating Bulbar Paralysis: Polyuria and Polydipsia: Return of Cancerous Gronths to the Base of the Skull, and cariones parts of the Body, after Frecision of the Mamma.

Antecedent History.-A. S., aged 54, married, cook. The patient stated when she was first examined, that she laad been in good health, and had not suffered from syphilis or other diseases, till the year 1869. She then discovered a tumour in her right breast, which was removed by Mr. Marshall, of University College Hospital. Microscopical examination of the morbid lesion demonstrated it to be scirrhous cancer. After this, the patient contiuued well for some years; but, in 1872, it was noticed that hardness appeared in the cicatrix of the above-mentioned opera. tion. This slowly increased during two and a half years, finally developing into a tumour, which was again removed by the same surgeon. This also was found to be of a cancerous naturc. Subsequently to this, the general bealth remained good till about two years ago, when the patient suffered from general weakness, malaise, and other indefinite symptoms. These continuel to increase till about six months ago, when she began to experience constant thirst, and to pass large quantities of urine. Shortly after this, it was observed that the tongue was shrivelled and protruded to one side, and that her speech was altered. These symptoms have continued since.

Condition on Examination.-The patient is found to be a pale, sallow, delicate-looking woman. She conplains of languor and general weakness. She also suffers from noises in the cars. Otherwise, there are no definite complaints. The intelligence is normal, although the patient is nervous and emotional, which she accounts for by living in constant dread of $a$ brutal husband. The motions of the eycballs and pupils are normal, the sight is unaffected, and the ophthalmoscopic appearances of the fundus of the eye are healthy. At rest, the face is straight, the motions of its lower parts are especially very limitcd, and the features are smooth and expressionless. The actions of the
lips are particularly deficient; the patient cannot whistle or spit; she has difficulty in opening the mouth, showing the teeth, etc., and the lower lip hangs down so that the saliva constantly trickles down the chin. The articulation is somewhat indistinct and mumbling, but not to a great extent. The sensibility of the skin of the face is normal. The tongue, when protruded, is much twisted to the left side; its movements are rery slow and imperfect, and it can with difficulty be pushed beyond the teeth. it is small, as a whole, and the left side is distinctly more atrophied than the right, it being much shrivelled and puckered. Its sensibility is noemal. The patient is partially dcaf with the right car, from which occasionally there is a purulent disoharge. Taste and smell are normal. There is no diffenlty in swallowing. The fnnc- 
tions of the other cranial nerves are healthy. There is no actual pereais of the limbs, but great musenlar weakness and languor is complained of. The entire body is thin, but there is no special atrophy of any of the muscles. In the right mammary region, there is a healthy linear cicatrix, about three inches long, and the breast on that side is absent. The patient complains of constant thirst ; and, while under observation, passed from eights-five to one hundred and thirty-five ounces of urine in the twenty-four hours, the specific gravity of which was 1004, containing no trace of sugar or albumen. The functions and organs of the body are otherwise normal. Electrical examination shows that, when faradism and galvanism are applied to the facial nerve trunks on both sides, there is great diminution of response-very strong currents being required to produce muscular contractions. The same ensues when the faradic stimulus is applied directly to the facial muscles; but to galvanism, these respond with vigour-the action being prolonged, and the anodal closurc contraction equalling the cathodal closure contraction $(A C C=C C C)$. When faradism is applied to the left side of the tongue, there is no response even to its strongest powers; but, with the same to the right, there is slight reaction. Galvanism to the former induces increased contractions, as compared to healthy muscles and to the other side, the anodal closure contraction exceed. ing the cathodal closure contraction $(\triangle C C>C C C)$. To the latter, the responses appear normal. The reaction of the other nerves and muscles of the body is as in health. (July 1882.)

Progress of the Case. - The patient remained under observation for about two months in the Westminster Hospital, under the care of Dr. Sturges, before she died. Her condition in no way essentially changed. She gradually became weaker and more feeble; was constantly confined to bed; finally, was very drowsy and apathetic, vomited her food, and slowly sank without exhibiting any new symptoms.

Past Xortem Bxamination, eighteen hours after death. - The body is much emaciated. There is no trace of disease in the cicatrix over the right mammary region. There is slight purulent discharge from the right ear. The cranial bones are soft and brittle, and in the inner aspect have a worm-eaten appearance, which extends over the base of the skull. The dura mater is adherent to the bone, is much thickened, and covered with numerous white, flat, projecting patches the size of millet-seeds, which subsequent microscopic examination showed to be of cancerous structure. The various parts of the brain itself are normal, except that at the right temporo-sphenoidal region, adjacent to the petrous portion of the temporal bone, there is a portion of the grey matter softened, about the size of a sixpence, evidently connected with the neighbouring osseous disease. Scattered over the base of the skull are numerous patches of degenerated bone, varying in size from a pea to a shilling. These masses are soft and friable, and irregularly dispersed. On careful examination, it is found that these morbid processes more particulary involve the internal auditory meatus and condyloid foramen on both sides, and apparently press on both the facial and hypoglossal nerves. The central aspects of these nerves are healthy in appearance; but the distal ends of the hypoglossals are, to the naked eye, distinctly atrophied, especially on the left side. The tongue is small and shrirelled; on the left side, it is much wasted, and the muscular substance is pale and yellow in colour. The pons, medulla, and other cranial nerves are, to all appearances, normal; and the remainder of the brain is healthy, except that a fibrinous clot oocupies the right lateral sinus. Throughout both pleurse and lungs are scattered various secondary growths, of the same appearance as those found in the dura mater. Some of the ribs are soft and friable, and in the same condition as the bones of the skull. In the substance of the liver are numerous growths varying in size from a pea to a marble. The spleen and pancreas are normal. Attached to the uterus is a tumour about the size of a hen's egg. The other organs of the body are healthy.

Dr. Byrom Bramwell of Edinburgh was good enough to make a histological examination of the different tissues in this case, and the following is abstracted from his notes. "I find no essential lesion in the medulla. All the cells of both sides are fatty (but this is not unusual), and there are some amyloid bodies in the grey matter of the floor of the fourth rentricle; but the nuclei of the hypoglossals are practically healthy, and so are the nerve-strands proceeding from them. I have not yet cut across the hypoglossal nerves themselves, but the naked-eye examination was quite conclusive. The tongue shows well-marked atrophy-a simple and not fatty atrophy - apparently of the muscular fibres, and the degeneration of some of the transversely divided nerve-bundles is well seen in some of the sections." Microscopical examination also deter- mined that all the abnormal proceses, whether in bone or tivoues, were of a cancerous nature.

Commentary. - This case presents features of interest from both a pathological and clinical point of view. I propose to direct special attention to, 1 , the cancerous condition; 2, the poljuria and polsdipsia ; and 3 , the peripheral nerve-lesions.

The Cancerous Condition. - It is sufficient to state that this case affords an illustrative instance of the recurrence of cancer, both locally and generally, after surgical operation. In 1869 , the breast was removed, and microscopic examination at the time demon. strated the tumour to be of true scirrholis nature. In 1872, the disease reappeared in the cicatrix left by the operation, and this was in 1875 again excised. In 1882, the patient died, and cancerons growths were found in rarious parts of the body, while the tissues in the neighbourhood of the former disease were bealthy.

The Polyuria and Polydipsia.-.-The post mortem appearances in this case, as in so many others, throw little light on the morbid anatomy of polyuria. That injury to nervous structures may induce this disease, as well as glycosuria, is well established; and that there is a close connection between these two affections appears probable, as usually both occur in the same patient, and the one may be transformed into the other. The physiological researches of Claude Bernard demonstrated that injury to the fourth rentricle, at the central space between the origins of the auditory and pneumogastric nerves, caused glycosuria ; and Dr. Pavy found that experiments on the sympathetic ganglia were followed by the same condition. Bernard also ascertained that irritation of the fourth ventricle at a point a little higher up than the one already mentioned, induced polyuria alone, without the presence of sugar in the urine, and stimulation of another spot close by was followed by albuminuria. Although it hastbeen proved that irritation of these points in the fourth ventricle causes these effects, there is no evidence that disease of these localities need be present when polyuria or glycosuria exists; on the contrary, we find that in most of the examinations made in cases of such disease, this portion of the brain has been found in a healthy condition. Injuries of other parts of the encephalon hare been seen to be followed by the same symptoms. Fischer collected twenty cases in which polyuria and glycosuria resulted from blows on the head, and instances have been recorded of the same following diseases of the brain, and even after strong mental emotions. I believe that polyuria is by no means an uncom. mon aymptom of cerebral lesions of various kinds and in different localities, and these in no way directly connected with the fourth ventricle. In a case of polyuria of long standing, which was under my observation, the patient died from the effects of a surgical operation. He had never, during life, shown any symptoms of cerebral disease, but after death a tumour, the size of a pigeon's egg. was found in the brain, and situated in the right temporo-sphenoidal region. In another instance of a gentleman with polyuria, who died from abdominal disease, there was found an abscess in the parietal lobe. In two other cases where facial paralysis, glycosuria, polyuria and albuminuria existed, I discorered disease of the cortex of the brain after death, the base and fourth rentricle being apparently normal. Finally, in the case before us, this last situation was healthy, and other parts of the cncephalon diseased. Besides these five cases, in which an opportunity was afforded of seeing the post mortem appearances, I have met with many other instances of polyuria accompanying lesion of the brain, in which there was no reason to suppose that the medulla was in any way directly implicated. Although the pathology of this affection is as yet very obscure, these facts wonld seem to indicate that if physiology teaches ns that the fourth ventricle of the brain in some way exerts an influence over the production of polyuria and glscosuria, and that its irritation or destruction interferes with that process, it is not necessary that this locality itself be directly affected, and that morbid conditions elsewhere in the cerebrum may, by reflex action or otherwise, so modify its function as to induce pathological effects. What special portions of the encephalon require to bo involved, or whether disease at any part of its structure may have the same result, we do not know; but from both pathological observation and clinical experience, it would scem that various lesions in different parts of the brain, none of them directly implicating the fourth ventricle itself, may lend to the symptoms nuder consideration. Thus, assuming the cells in the fourth ventricle, to be the originators of this polyuric function, and these in turn capable of being influenced by reflex action, pressure, or otherwise from
numerous sources, it is obvious that various lesions, both within and without the brain, may be the cause of the disease. This theory secms to be borne out by the fict that the centre in question 
is usually found healthy, and that polyuria is associated with many forms of cerebral abnormality situated in different localities.

The Peripheral Nerve-Lesions.-When this patient came under observation, the lower parts of the face were found expressionless, and with impaired motion; the lower lip hung down, saliva trickled from the mouth, the lips were inactive, the food collected in the month, the tongue was sluggish in its movements, and was much atrophied, and the speech was hesitating and mumbling. In short, the case presented all the features of typical glosso-labial paralysis. The patient had visited various hospitals, and her disease had invariably been diagnosed as bulbar paralysis, to which there can be no question it presented the strongest resemblance. On applying electrical tests, however, reactions were obtained which were not anticipated. In bulbar paralysis, the nerve-trunks and their terminations remain healthy throughout the entire progress of the disease, or, at least, till its very latest stages, and the muscular fibres remain normal for a considerable period, after which they slowly undergo degenerative change. Hence the faradic current, when applied to the nerve-trunks or to the muscles, induces normal reactions; and galvanism, acting on the former, is followed by the same, but, on the latter, indicates both quantitative and qualitative alterations. In the case before us, which was a comparatively recent one, totally different reactions were discovered. The trunks of both facial nerves, if not absolutely insensitive to both currents, were greatly diminished in excitability. Faradism to the facial muscles caused little or no contraction, whereas galvanism induced vigorous action with the polar reactions reversed. Faradism, again, to the muscles of the tongue was followed by no response, while galvanism was succeeded by increased action, and inverted polar reactions. Such phenomena are evidences of neuro-muscular paralysis, and not those we are accustomed to meet with as a result of central disease, in which, as above stated, the nerve-trunks and their extremities remain healthy throughout. During the life of the patient, there might have been some hesitation in making a positive diagnosis, as, in spite of the physical demonstration just described, it seemed most improbable that both hypoglossal and both facial nerves should be degenerated, learing the other cranial nerves and functions of the brain intact. Such, however, the post mortem examination showed to be the case, as extensive disease of the base of the skull, not sufficiently pronounced to cause gross pressure elsewhere, involved the foramina through which the above nerves passed, evidently pressing on their structure, as evidenced by their peripheral degeneration, and their healthy proximal extremities.

The patient, on interrogation, said that she experienced slight numbness of the face and difficulty in mastication, but no definite objective signs of this could be determined. It is, however, not improbable that, although the trunks of both fifth nerves appeared healthy, they also may have been slightly involved in the disease. The portio dura, on one side, was evidently implicated, accounting for the deafness during life, which may also be explained by the conditions found after death.

This case is a striking example of the great importance of electrodiagnosis in the investigation of obscure paralyses. Without its aid, this patient would certainly have been considered to be suffering from bulbar paralysis; whereas, by its assistance, we were enabled to diagnose, in the face of great improbabilities, the existence of peripheral, and not of central, disease.

A GLARING illustration of the great amount of ignorance prevailing among mothers, in respect to the proper feeding of infants, is shown in a case which recently came before Mr. George Collier, the evidence of which showed that a child, aged eleven months, being fretful from birth, the mother had given it anything to eat which it fancied. The result was that it had breaking ont on its body and convulsions; and, ultimately, it had a fit, and it also seemed to have had two falls before Christmas. Having another fit, a doctor was sent for ; but, before a bath could be got ready, it died of convulsions, certainly set up by improper feeding. The coroner, wisely dilating upon the crass ignorance of mothers, as shown repeatedly before him, and the gross stupidity of giving a child of tender years meat and other food which its digestive organs found it wholly unable to assimilate, said that mothers in this matter, and many others, would never grow wiser until the duties of maternity became part of the curriculum of the public schools. The jury said they hoped the case would carry its moral to other mothers, and returned a verdict in accordance with the medical evidence.

\section{REMARKS ON THE DEATH-RATE OF AN ESSTHESIA, WITH AN ACCOUNT OF SIX FATAL GASES.}

\author{
BY W. ROGER WILLIAMS, F.R.C.S., \\ Surgical Registrar to the Middlesex Hospital.
}

DuRING the last few years, an impression has arisen in the profession, and has been communicated to the general public, that the indnction of anzesthesia is a much more dangerous proceeding than was formerly believed. The numerous fatal cases lately recorded in the journals have proved, in the clearest manner possible, that this impression is only too well founded on fact.

$\mathrm{M}$ y own experience, which there is no reason to regard as singular, leads me to believe that the real dangers of this proceeding are still very greatly underestimated. The majority of fatal cases are hushed up; only a few find their way to the journals. Six deaths from this cause, none of which have been made public, have come under my immediate notice during ten years of hospital work.

On an average, I have, probably, witnessed the induction of anæsthesia abont four times a week, during the whole of this period-an estimate over, rather than under, the mark. Hence, the mortality in these cases may be roughly stated at 1 in 350 inhalations. But it should be remembered that this does not represent the whole of the danger, for, in a still larger proportion of cases, alarming symptoms supervened, and fatal results were only narrowly avoided. As far as I can judge, the number of times that chloroform and ether were sererally administered was about equal. Five deaths resulted from the use of the former agent, and one from that of the latter. In the former category, I have included three fatal cases, due to the use of a mixture of two parts of chloroform with three parts of ether; becanse, as an anæsthetic agent, the action of this mixture precisely resembles that of chloroform.

Calculated on this basis, then, the death-rate for chloroform would be 1 in 208 inhalations; and that for ether, 1 in 1,050-the lowest estimate possible. Although the total number of cases on which this statement is based is not so large as, under the circumstances, might be desired, especially as regards ether; I think, nevertheless, it may be accopted as conveying a more correct idea of the dangers actually involved, than any of the statistics usually quoted.

In the JOURNAL of December 30th, 1882, the death-rate for chloroform is given as 1 in 2,873 inhalations, and that for ether as 1 in 23;204-a ridiculously low estimate. Perhaps some of your readers will be able to explain these remarkable discrepancies, and to decide which statement most nearly approximates the truth. I ought to add that my field of observation has been a wide one, not confined to one institution or one method, but comprising several metropolitan and provincial hospitals; hence I think it may fairly claim to be typical of the kind of practice it represents.

I now propose to give a short account of each of these cases, and then to conclude with a few additional remarks.

CASE I.-This patient was a stout, well-built, florid man, aged 37, rather above the usual height. He was in a robust state of health at the time of the fatality; and he had previously-been of moderately temperate habits. He was sent from the out-patient department to the operation-theatre, to have a small piece of dead bone removed from the end of the stump of his right forearm. The limb had been amputated a little below the elbow-joint, about a year previously, for a bad crush involving the hand, wrist, etc.; and anæsthesia had then been induced without any trouble, by the gas-andether method, with Clover's apparatus.

For an operation of such a trifling nature, gas alone was deemed sufficient, and be was nearly under its influence, when it was found that the supply in the reservoir was exhausted. ('hloroform was now sent for; and, during the delay thus involved, the patient completely recovered consciousness, and said he thought he had been for a ride in the train. Abont a drachm of chloroform having been poured without measurement on to a piece of folded lint, the administration was effected by holding this rather closely orer the patient's mouth and nose. 'To prevent the dissipation of the rising vapour, a large towel was thrown over the patient's face, as well as over the administrator's hand. By this means, after a well-marked stage of muscular excitement, sufficient anæsthesia was induced in less than three minutes. Immediately after the first incision, it was noticed that the patient had stopped breathing; that the face was livid; and that the pulse had ceased to beat. The face then rapidly became pallid; bnt subsequently resumed much of its duskiness. These symptoms snpervened suddenly, without stertor or any other 